\title{
Bmi-1 in gallbladder carcinoma: Clinicopathology and mechanism of regulation of human gallbladder carcinoma proliferation
}

\author{
KAI JIAO $^{1}$, WEIJIAO JIANG ${ }^{2}$, CHUNYANG ZHAO ${ }^{1}$, DEWANG SU $^{3}$ and HAOMIN ZHANG ${ }^{1}$ \\ Departments of ${ }^{1}$ General Surgery and ${ }^{2}$ Rotation, The Second Affiliated Hospital of Qiqihar Medical University, \\ Qiqihar, Heilongjiang 161006; ${ }^{3}$ Department of General Surgery, First Affiliated Hospital \\ of Jiamusi University, Jiamusi, Heilongjiang 154000, P.R. China
}

Received January 21, 2019; Accepted May 7, 2019

DOI: 10.3892/ol.2019.10408

\begin{abstract}
Expression of Bmi-1 in gallbladder carcinoma and its clinicopathology and mechanisms of regulation of human gallbladder carcinoma cell proliferation were investigated. Fifty cases of gallbladder carcinoma specimens and 15 normal gallbladder tissues were subjected to immunohistochemical staining to detect the expression of Bmi-1 gene in gallbladder carcinoma and normal gallbladder tissues. Clinicopathological features were compared and analyzed. Bmil-si RNA and Bmi1-NC vectors were transfected into GBC-SD gallbladder cancer cell lines. Expression of Bmi-1 in GBC-SD-Bmil-si RNA, GBC-SD-Bmil-NC and GBC-SD cells was detected by RT-qPCR. Cell proliferation was detected by CCK-8 assay. Flow cytometry was used to detect cell apoptosis. Protein expression was detected by western blot analysis. The positive expression rate of Bmi-1 protein in gallbladder carcinoma tissues was significantly higher than that in normal gallbladder tissues $(\mathrm{P}<0.05)$. Expression of Bmi-1 protein in gallbladder carcinoma was correlated with tumor differentiation and stage $(\mathrm{P}<0.05)$. Expression level of Bmi-1 in GBC-SD-Bmil-si RNA was significantly lower than that in GBC-SD-Bmil-NC and GBC-SD cells. The apoptosis rate of GBC-SD-Bmi1-si RNA cells was significantly higher than that of the two control groups. Compared with the control groups, the expression of anti-apoptotic protein $\mathrm{Bcl}-2$ in GBC-SD-Bmil-si RNA cells decreased, while the expression of proapoptotic protein Bax and caspase 3 increased, and the expression levels of cyclin D1 and CDK2 decreased. Positive expression rate of Bmi-1 protein in gallbladder carcinoma tissues was significantly higher than that in normal gallbladder
\end{abstract}

Correspondence to: Dr Haomin Zhang, Department of General Surgery, The Second Affiliated Hospital of Qiqihar Medical University, 37 Zhonghua Road, Qiqihar, Heilongjiang 161006, P.R. China

E-mail: jiaokai0116@126.com

Key words: gallbladder carcinoma, Bmi-1, clinicopathology, mechanism study tissue. Following inhibition of the expression of Bmi-1 in gallbladder cancer cell line GBC-SD, the growth cycle of cancer cells was prolonged and apoptotic rate increased. The results showed that a decreased expression of cyclin D1 and CDK2 may lead to delayed cell proliferation, decreased expression of anti-apoptotic protein Bcl-2, increased expression of proapoptotic protein Bax and caspase 3, leading to increased apoptosis.

\section{Introduction}

Gallbladder carcinoma is the most common malignant tumor of the biliary system (1). Its incidence ranks seventh among digestive tract tumors (2). Gallbladder cancer cells can spread in the early stage through direct infiltration, lymphatic metastasis and blood transfer. The majority of patients are diagnosed at an advanced stage, which is not suitable for surgery, leading to poor postoperative survival $(3,4)$. Therefore, in-depth study of key molecules in the development of gallbladder cancer, exploring the molecular mechanism of gallbladder cancer proliferation, and screening for effective diagnostic and therapeutic targets is critical for the future treatment of gallbladder cancer.

The B-cell specific Moloney murine leukemia virus integration site $1(B m i-1)$ is a proto-oncogene in the polycomb group gene family and is a transcriptional repressor. Human Bmi-1 gene is located in the short arm 13 region of chromosome 10 and encodes a protein of 326 amino acids expressed in the cytoplasm and chromatin. Bmi-1 gene plays an important role in cell cycle, cell immortalization and senescence, and self-renewal and differentiation of stem cells. The role of Bmi-1 in tumor formation has become a research hotspot in different types of cancer, such as ovarian (5), esophageal (6) and cervical cancer (7). However, whether Bmi-1 is involved in the development of gallbladder cancer and its role in gallbladder cancer is unclear. Based on a series of molecular and biochemical experiments, the aim of the study was to explore the mechanism of the action of Bmi-1 in the occurrence and development of gallbladder carcinoma, and provide a theoretical basis for understanding the molecular mechanism and clinical treatment of gallbladder cancer. 
Table I. miRNA oligomeric single-stranded DNA sequences.

Items

Primer sequence 5'-3'

Bmil-si RNA shRNA

Bmi1-NC shRNA

\author{
Forward: GATCCGGTATTCCCTCCACCTCTTCTTTCAAGAGAAGA \\ AGAGGTGGAGGGAATACCTTTTTTGGAAG \\ Reverse: AATTCTTCCAAAAAAGGTATTCCCTCCACCTCTTCTTCT \\ CTTGAAAGAAGAGGTGGAGGGAATACCG \\ Forward: GATCCATACAACTCGCATCTGACATTCAAGAGAATACA \\ TGACATCAATCTGGTTTTTTGGAAG \\ Reverse: AATTCTTCCAAAAAAATACAACTCGCATCTGACATCTC \\ TTGAAAGAAGAGGTGGAGGGAATACCG
}

\section{Patients and methods}

Patients and cell culture. Fifty patients with gallbladder cancer (20 males, 30 females, aged 35-78 years, mean: 58 years) who underwent surgical excision were selected from The Second Affiliated Hospital of Qiqihar Medical University (Qiqihar, China) during the period January 2011 to August 2017. The patients included 19 cases with high differentiation, 13 cases with moderate differentiation, and 18 cases with low differentiation. According to TNM staging of gallbladder carcinoma, there were 18 cases in stage I-II and 32 cases in stage III-IV. None of the patients received radiotherapy and/or chemotherapy prior to surgery. There were 29 cases with gallstone invasion and 17 cases with other organ invasion. Another 15 cases of normal gallbladder tissue were selected as the control group, all from patients with intrahepatic bile duct stones or liver tumors who underwent right hepatectomy (no stones and tumor invasion in the gallbladder), including 6 males and 9 females, aged 32-73 years, with a mean age of 52.5 years.

The study was approved by the Ethics Committee of The Second Affiliated Hospital of Qiqihar Medical University. Patients who participated in this research had complete clinical data. Signed informed consents were obtained from the patients or the guardians.

Pathological specimens were obtained from patients undergoing cholecystectomy during the same period. There was no significant difference in sex and age between the gallbladder cancer group and the normal gallbladder tissue group. The specimens were fixed with $10 \%$ formaldehyde, dehydrated and dipped in wax to make $4 \mu \mathrm{m}$ paraffin sections. Human gallbladder cancer cell line GBC-SD (preserved in the Laboratory of The Second Affiliated Hospital of Qiqihar Medical University) was cultured in RPMI-1640 medium (1559231, Gibco; Thermo Fisher Scientific, Inc., Waltham, MA, USA) containing 10\% fetal calf serum (MB5175, Dalian Meilun Biological Technology Co., Ltd., Dalian, China) at $37^{\circ} \mathrm{C}$ and $5 \% \mathrm{CO}_{2}$ under constant temperature. When cells grew to $70-80 \%$ confluency, they were digested with $0.25 \%$ trypsin and passaged.

Bmil-siRNA and Bmil-NC (negative control) vectors (vector pSUPER) were constructed by Shanghai Biotech, Shanghai, China and sequence of Bmil-si RNA and Bmil-NC are shown in Table I.
Immunohistochemical staining for detection of Bmi-1 expression in gallbladder carcinoma. After dewaxing with xylene for 10 min x 3 and dehydration with gradient alcohol (85\% ethanol, $95 \%$ ethanol and absolute ethanol), tissue sections were incubated with $3 \% \mathrm{H}_{2} \mathrm{O}_{2}$ for $8 \mathrm{~min}$, followed by PBS washing ( 5 min $\times 3$ ). After non-immune calf serum was blocked for $20 \mathrm{~min}$, the tissue sections were washed with PBS (5 min x 3). Following removal of excess PBS solution, tissue sections were incubated with anti-mouse anti-human Bim-1 (cat. no. MAB33342, R\&D Systems, Inc.; 1:500 dilution) overnight in a refrigerator at $4^{\circ} \mathrm{C}$. After PBS washing $(5 \min \times 3)$, the tissue sections were incubated with biotinylated secondary antibody (1:500 dilution, cat. no. 515-065-003, Jackson ImmunoResearch Laboratories, Inc.) for $20 \mathrm{~min}$ at room temperature. After PBS washing ( 5 min $\times 3$ ), the tissue sections were incubated with freshly prepared DAB solution and observed under a microscope (Eclipse Ni-E/Ni-U, Nikon). Determination of immunohistochemical results: 5 high-power visual fields were randomly selected for cancer cell counting, and comprehensive scoring was performed based on positive expression cells and positive staining intensity. Scoring rules: total score $=\mathrm{A} \times \mathrm{B}$, where ' $\mathrm{A}$ ' represents the percentage of positively expressed cells (A <10\%, 0 point; $10-25 \%, 1$ point; $26-50 \%, 2$ points; $51-75 \%, 3$ points; $\mathrm{A}>75 \%, 4$ points), ' $\mathrm{B}$ ' is the staining intensity of positive cells (colorless, 0 point; light yellow, 1 point; yellow, 2 points; brown, 3 points). Total score was: $<2$ is negative (-), 2-4 is weak positive (+), 5-8 is moderately positive $(++)$ and $9-12$ is strongly positive $(+++)$, and $>2$ points are collectively referred to as positive expression.

qPCR detection of Bmi-1 expression in gallbladder carcinoma. Total RNA was extracted from gallbladder cancer and normal gallbladder tissues using TRIzol RNA extraction kit (WLA088a, Wanleibio Co., Ltd.). After measuring the total RNA concentration, samples with A260/A280 of 1.8-2.0 were selected for subsequent experiments. GAPDH was used as an internal reference. Reverse transcription and PCR amplification were carried out using the RT-PCR kit (RR037A, Takara Bio, Inc.). Primer sequences are shown in Table II (synthesized by Sangon Biotech Co., Ltd.). RT-qPCR products were checked using $1 \%$ agarose gel electrophoresis.

Bmil-si RNA transfection and RT-PCR for detection of infection efficiency. GBC-SD cell suspension $\left(2 \times 10^{5} \mathrm{cells} / \mathrm{ml}\right)$ was 
Table II. Primer sequences for RT-PCR and qRT-PCR.

Gene name

Primer sequence 5'-3'

Product length (bp)

Bmi-1

Forward: GGATCCTCATCCTTCTGCTGATGCTG

GAPDH Reverse: GAATTCGCATCACAGTCATTGCTGCT

prepared and seeded in a 6-well plate. When $50 \%$ confluency was reached, Bmil-si RNA recombinant plasmid (miRNA oligo single-stranded DNA sequence is shown in Table II), Bmil-NC (mismatched sequence) and Lipofectamine 3000 were mixed and incubated for $30 \mathrm{~min}$ and then added to the 6 -well plate to transfect GBC-SD cell lines. The plate was incubated in $5 \% \mathrm{CO}_{2}$ and at $37^{\circ} \mathrm{C}$ in an incubator. Cells were divided into the GBC-SD-Bmi1-si RNA, GBC-SD-Bmi1-NC and GBC-SD groups. Transfection efficiency was detected by RT-PCR after $96 \mathrm{~h}$. RT-PCR was performed as follows: frozen tissues were taken out from the liquid nitrogen tank, and cDNA was reverse transcribed according to the instructions of reverse transcription kit (primers shown in Table II, produced by Sangon) following conditions of $65^{\circ} \mathrm{C}$ for 5 $\min , 42^{\circ} \mathrm{C}$ for $60 \mathrm{~min}$ and $70^{\circ} \mathrm{C}$ for $5 \mathrm{~min}$ and then placed on ice to cool after termination reaction and preserved. Using GAPDH as an internal reference, the expression of Bmi-1 in each cell line was detected as per the protocol of the RT-qPCR kit (RR037A, Takara Bio, Inc.). Reaction conditions were 40 cycles of $95^{\circ} \mathrm{C}$ for $10 \mathrm{sec}, 55^{\circ} \mathrm{C}$ for $20 \mathrm{sec}, 72^{\circ} \mathrm{C}$ for $20 \mathrm{sec}$ and $79^{\circ} \mathrm{C}$ for $20 \mathrm{sec}$. At the same time, the chain dissolution curve of the amplified product was detected with the conditions of $95^{\circ} \mathrm{C}$ for $2 \mathrm{~min}, 60^{\circ} \mathrm{C}$ for $20 \mathrm{sec}, 72^{\circ} \mathrm{C}$ for $20 \mathrm{sec}$ and $99^{\circ} \mathrm{C}$ for $15 \mathrm{sec}$. Data normalizations were performed based on the $2^{-\Delta \Delta \mathrm{Cq}}$ method (8).

CCK- 8 assay detection of cell proliferation. The transfected cells of each group were trypsinized, and seeded in a 96 -well plate ( 3 replicate wells per cell) at $2 \times 10^{3}$ cells/well After $24 \mathrm{~h}$ of culture, $10 \mu \mathrm{l} /$ well of CCK-8 reagent was added (40203ES60, Shanghai Yu Sheng). After incubation for an additional $2 \mathrm{~h}$ in the incubator, the corresponding OD values were measured using a microplate reader (measuring wavelength: $450 \mathrm{~nm}$, reference wavelength: $650 \mathrm{~nm}$ ). Subsequently, measurement was performed every $24 \mathrm{~h}$ for 4 days, and the corresponding cell proliferation curve was plotted.

Flow cytometry detection of apoptosis. Transfected cells were cultured in the logarithmic growth phase (after $72 \mathrm{~h}$ ). Cells $\left(2 \times 10^{6}\right)$ were treated with trypsin and transferred to a $10 \mathrm{ml}$ centrifuge tube. Pre-cooled PBS buffer without calcium and magnesium was added. After centrifugation at $157 \mathrm{x} g$ for $5 \mathrm{~min}$ at $4^{\circ} \mathrm{C}$, the cells were washed 3 times and $100 \mu \mathrm{l}$ of binding buffer was added and incubated with the cells in the dark for $10 \mathrm{~min}$. Annexin V-FITC and $10 \mu \mathrm{l}$ of PI stain (MA0220, Dalian Meilun Biological Technology Co., Ltd.) were added and incubated in the dark for $25 \mathrm{~min}$. Detection of apoptotic cells was performed by flow cytometry.
Total protein extraction and western blot analysis. After the transfected cells were cultured in a 6-well plate, the cells were washed well with pre-cooled PBS for 1 min $x 3$. After PBS was discarded, cell lysate was added, mixed, and the mixture was transferred to a $1.5 \mathrm{ml}$ centrifuge tube, followed by centrifugation at $22,600 \mathrm{x} \mathrm{g}$ for $5 \mathrm{~min}$ at $4^{\circ} \mathrm{C}$. After centrifugation, the supernatant was removed from the total protein of the cells. Total protein was stored at $-80^{\circ} \mathrm{C}$. BCA protein quantification kit was used to quantify the protein extracted from each group of cells. Protein $(10 \mu \mathrm{g})$ was subjected to $10 \%$ SDS-PAGE electrophoresis. Following gel transfer to PVDF membrane, the membranes were blocked in 1X PBS containing 5\% skim milk powder for $3 \mathrm{~h}$ at room temperature. Subsequently, the corresponding antibodies were diluted $(1: 1,500)$ in blocking solution (rabbit anti-human Bax: cat. no. LS-C210507, LSBio; rabbit anti-human caspase 3: cat. no. LS-C746939, LSBio; rabbit anti-human Bcl-2: cat. no. LS-B6548, LSBio; rabbit anti-human cyclin D1: cat. no. LS-B3452, LSBio; rabbit anti-human CDK2: cat. no. ab32147, Abcam; rabbit anti-human $\beta$-actin antibody: cat. no. ab8227, Abcam) and the membranes were incubated in first anti-diluent overnight at $4^{\circ} \mathrm{C}$. After washing with TBST $8 \mathrm{~min} x 3$, membranes were incubated with secondary antibody (1:2,000 diluted, mouse anti-rabbit IgG, cat. no. LS-C60914, LSBio) for $2 \mathrm{~h}$ at room temperature. Then the membrane was washed with TBST for 7 min x 3, ECL (Amersham Pharmacia Biotech) was used to develop signals.

Statistical analysis. The data were analyzed by SPSS23.0 professional statistical software. Measurement data were expressed as mean \pm standard deviation. The countable data were compared by $\chi^{2}$ test. Comparisons between groups were analyzed by one-way ANOVA and Scheffe post hoc test. $\mathrm{P}<0.05$ was considered to indicate a statistically significant difference.

\section{Results}

Immunohistochemical staining for detection of Bmi-1 expression. Positive expression rate of Bmi-1 protein in 50 cases of gallbladder carcinoma was $84 \%$ (42/50), and the positive expression rate in normal gallbladder tissues was $40 \%(6 / 15)$. Data analysis showed that the positive expression rate of Bmi-1 protein in gallbladder carcinoma tissues was significantly higher than that in normal gallbladder tissues (control group, $\mathrm{P}<0.05$, Table III). In addition, Bmi-1 protein is weakly positive or not expressed in normal gallbladder tissues (Fig. 1A), while in gallbladder carcinoma tissues, the color was brownish yellow (or tan) in the nucleus and a small amount was expressed in the cytoplasm (Fig. 1B). 
Table III. Immunohistochemical staining for the detection of Bmi-1 expression.

\begin{tabular}{lccccr}
\hline & & \multicolumn{2}{c}{ Bmi-1 expression level } & & \\
\cline { 3 - 4 } Clinicopathological features & Cases & Negative (\%) & Positive (\%) & $\chi^{2}$ value & P-value \\
\hline Gallbladder cancer tissue & 50 & $8(16)$ & $42(84)$ & 14.927 & $<0.05$ \\
Normal gallbladder tissue & 15 & $9(60)$ & $6(40)$ & & \\
\hline
\end{tabular}

Table IV. Relationship between Bmi-1 protein expression and clinicopathological factors of gallbladder carcinoma.

\begin{tabular}{|c|c|c|c|c|c|}
\hline \multirow[b]{2}{*}{ Clinicopathological factors } & \multirow[b]{2}{*}{ Cases } & \multicolumn{2}{|c|}{ Bmi-1 expression level } & \multirow[b]{2}{*}{$\chi^{2}$ value } & \multirow[b]{2}{*}{ P-value } \\
\hline & & Negative $(\%)$ & Positive (\%) & & \\
\hline \multicolumn{6}{|l|}{ Sex } \\
\hline Male & 20 & $6(30)$ & $14(70)$ & \multirow[t]{2}{*}{2.681} & \multirow[t]{2}{*}{$>0.05$} \\
\hline Female & 30 & $3(10)$ & $27(90)$ & & \\
\hline \multicolumn{6}{|l|}{ Age } \\
\hline$<60$ years & 28 & $5(17.9)$ & $23(82.1)$ & \multirow[t]{2}{*}{0.931} & \multirow[t]{2}{*}{$>0.05$} \\
\hline$\geq 60$ years & 22 & $6(27.2)$ & $16(72.8)$ & & \\
\hline \multicolumn{6}{|l|}{ Differentiation } \\
\hline High/medium & 32 & $8(25)$ & $24(75)$ & \multirow[t]{2}{*}{9.182} & \multirow[t]{2}{*}{$<0.05$} \\
\hline Low & 18 & $2(11.1)$ & $16(88.9)$ & & \\
\hline \multicolumn{6}{|l|}{ TNM staging } \\
\hline I-II & 18 & $5(27.8)$ & $13(72.2)$ & \multirow[t]{2}{*}{6.521} & \multirow[t]{2}{*}{$<0.05$} \\
\hline III-IV & 32 & $4(12.5)$ & $28(87.5)$ & & \\
\hline \multicolumn{6}{|l|}{ Gallstones } \\
\hline Yes & 29 & $4(13.8)$ & $25(86.2)$ & \multirow[t]{2}{*}{0.107} & \multirow[t]{2}{*}{$>0.05$} \\
\hline No & 21 & $4(19.0)$ & $17(81.0)$ & & \\
\hline \multicolumn{6}{|l|}{ Other organ invasion } \\
\hline Yes & 17 & $2(11.8)$ & $15(88.2)$ & \multirow[t]{2}{*}{0.427} & \multirow[t]{2}{*}{$>0.05$} \\
\hline No & 33 & $6(18.2)$ & $27(81.8)$ & & \\
\hline
\end{tabular}

A

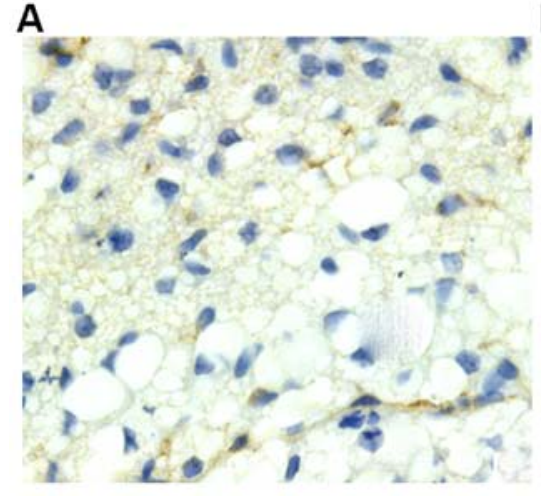

B

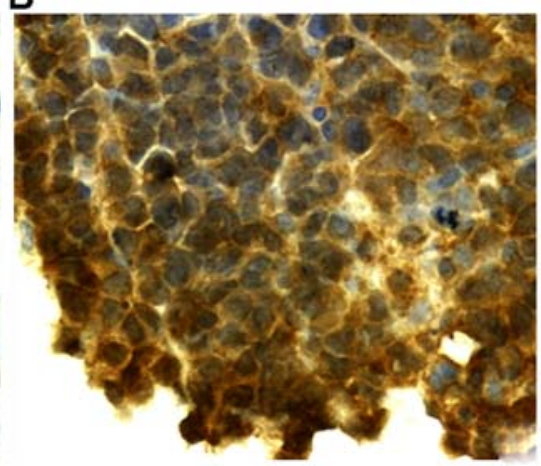

Figure 1. Weak positive expression of Bmi-1 protein in normal gallbladder tissues (A). Strong positive expression in gallbladder carcinoma tissues (B) (SP x400).

Analysis of the relationship between the expression of Bmi-1 in gallbladder carcinoma and clinicopathological factors. As shown in Table IV, positive expression of Bmi-1 protein in gallbladder carcinoma was correlated with the degree and stage of tumor differentiation. Positive expression of Bmi-1 in poorly differentiated gallbladder carcinoma was significantly higher than that in high/medium differentiated carcinoma, while positive expression of Bmi-1 in stage III and IV was significantly higher than that in I and II $(\mathrm{P}<0.05)$. Positive expression of Bmi-1 protein in gallbladder carcinoma was 


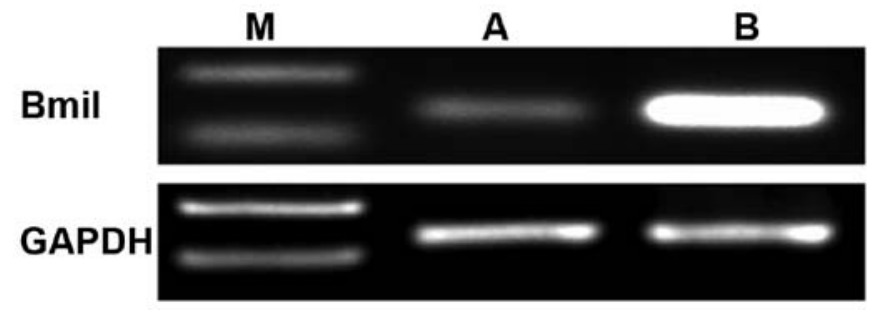

Figure 2. Expression of Bmi-1 in gallbladder carcinoma. (A) Normal gallbladder tissue; (B) gallbladder carcinoma tissue; M, Marker (bp).

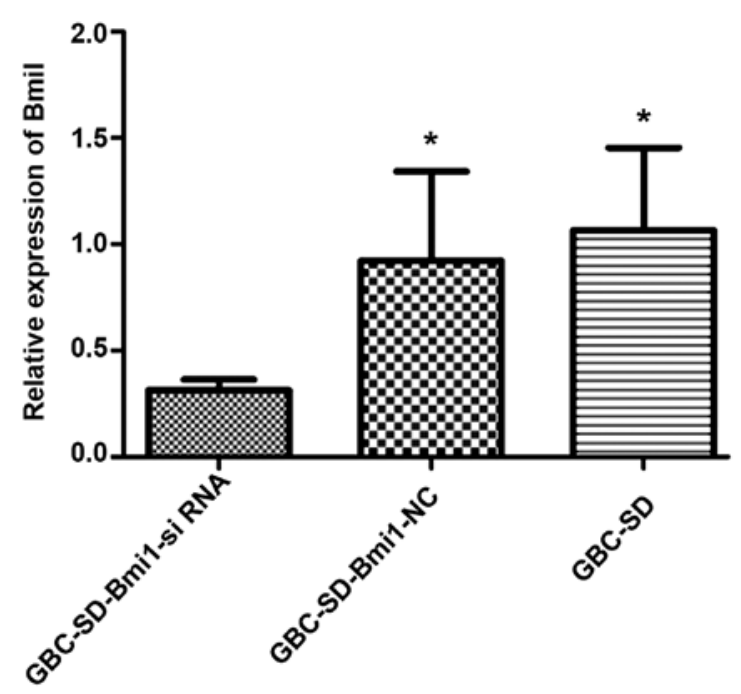

Figure 3. Expression of Bmi-1 in each cell line. ${ }^{\text {" }} \mathrm{P}<0.05$, compared with GBC-SD-Bmil-si RNA.

not associated with sex, age, presence of gallstones and other organ invasion $(\mathrm{P}>0.05)$.

qPCR detection of Bmi-1 expression in gallbladder carcinoma. Results showed that the mRNA expression level of Bmi-1 in gallbladder carcinoma tissues was significantly higher than that in normal gallbladder tissues (Fig. 2, $\mathrm{P}<0.05$ ).

RT-PCR detection of Bmi-1 expression level. Compared with human normal gallbladder cancer cell line GBC-SD and negative control GBC-SD-Bmil-NC cells, the expression level of Bmi-1 in GBC-SD-Bmil-si RNA transfected with Bmil-siRNA was significantly lower (Fig. 3, P<0.05). This result demonstrates that Bmil-si RNA can induce the degradation of Bmi-1 mRNA in gallbladder cancer cell lines.

CCK-8 assay detection of cell proliferation. As shown in Fig. 4 , at 72 and $96 \mathrm{~h}$, the absorbance of GBC-SD-Bmil-siRNA cells was significantly lower than that of control human normal gallbladder cancer cells GBC-SD and the negative control GBC-SD-Bmi1-NC cells. Therefore, the results indicate that the cell line GBC-SD-Bmil-si RNA constructed by the RNA interference technique grows slowly, that is, its growth is inhibited, and the growth cycle is prolonged.

Flow cytometry detection of apoptosis. As shown in Fig. 5, compared with GBC-SD and negative control

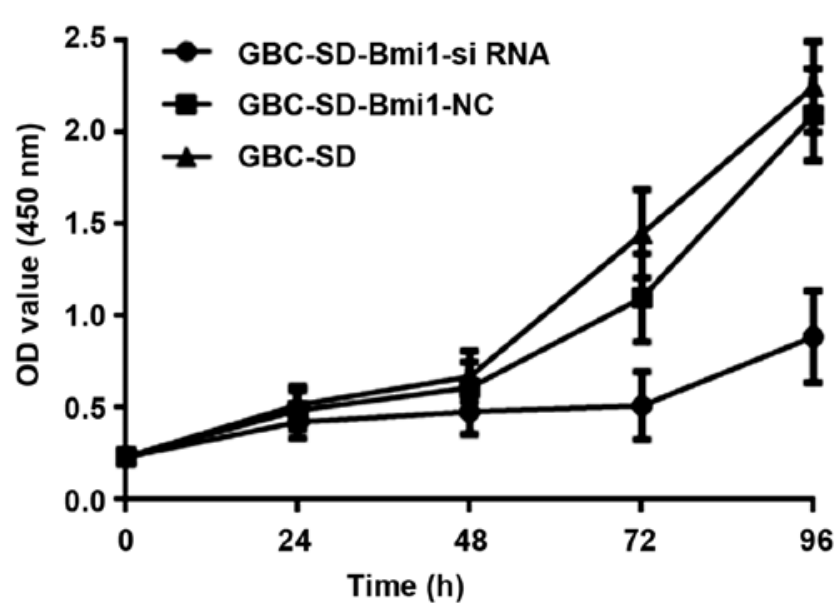

Figure 4. Proliferative capacity of each cell line.

GBC-SD-Bmi1-NC cells, the apoptosis rate of GBC-SD-Bmi1-si RNA cells was significantly higher than those of the other two groups ( $\mathrm{P}<0.05$, B4 quadrant as statistical object), i.e., the inhibited expression of Bmi-1 gene led to promoted apoptosis of gallbladder cancer cell line GBC-SD. This result is consistent with the CCK-8 experimental results.

Effect of Bim1-siRNA transfection on the expression of related proteins. As shown in Fig. 6, the expression level of the anti-apoptotic protein Bcl-2 in GBC-SD-Bmil-siRNA cells was decreased compared with GBC-SD and negative control GBC-SD-Bmil-NC cells. Expression level of Bax was increased, and the expression level of the apoptotic kinase caspase 3 was increased, which was consistent with the increase in the apoptotic rate of GBC-SD-Bmil-si RNA cells. In addition, the expression levels of the cyclins, cyclin D1 and CDK2, in GBC-SD-Bmi1-si RNA cells were decreased compared with the two control groups, which was consistent with the prolonged GBC-SD-Bmi1-NC cell proliferation cycle.

\section{Discussion}

Gallbladder cancer is the most common malignant tumor in the biliary system worldwide, and its geographical distribution is uneven, it is relatively rare in most countries, more common in countries such as India, Japan and Chile (9-12).

In China, the incidence of gallbladder cancer has also increased in recent years (13). Although recent data show that treatment efficacy of early gallbladder cancer is greatly improved (4), the prognosis of advanced patients is still not optimistic (14). Thus, worldwide scholars are committed to the in-depth research of the incidence and progression of gallbladder cancer in many aspects in order to achieve better prevention and treatment. Long-term in-depth research has found and identified a large number of related genes involved in gallbladder cancer. This study aimed to investigate the expression of Bmi-1 in gallbladder carcinoma and its clinicopathology and mechanisms of regulating human gallbladder carcinoma cell proliferation.

In this study, immunohistochemical staining showed that the positive expression rate of Bmi-1 protein in gallbladder 

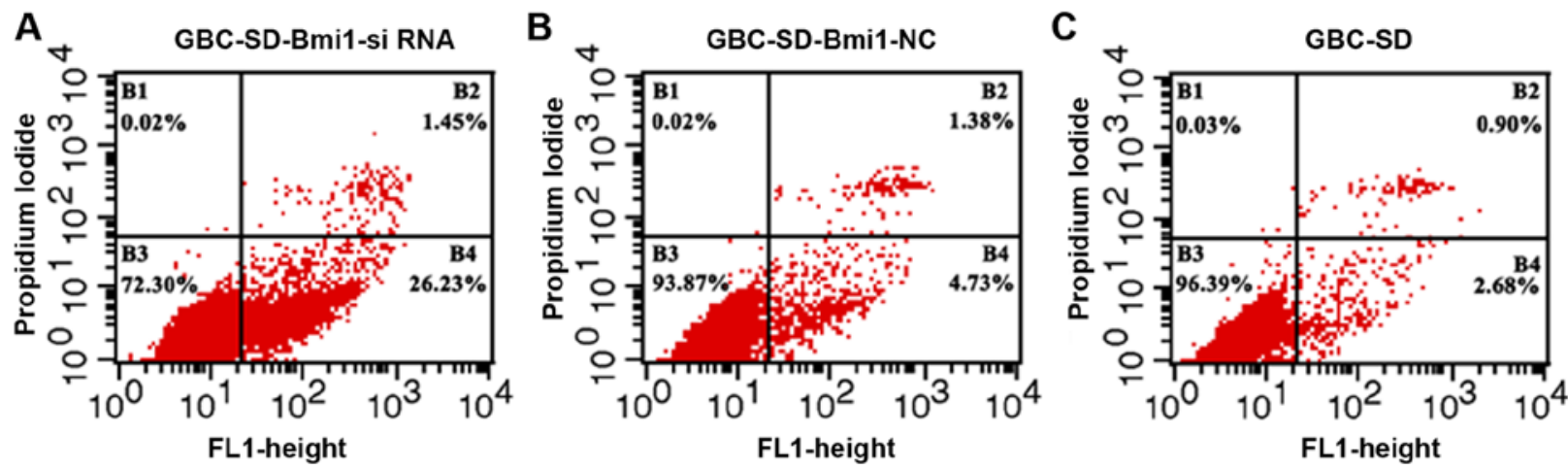

Figure 5. Bmi1-siRNA induces apoptosis in (A) GBC-SD-Bmi1-si RNA, (B) GBC-SD-Bmi1-NC, and (C) GBC-SD cells. B1 quadrant, necrotic cells; B2 quadrant, late apoptotic cells or necrotic cells; B3 quadrant, living cells; B4 quadrant, early apoptotic cells. B4 quadrant is the statistical object. The apoptosis rate in panel $\mathrm{A}$ is $26.23 \%$, in panel $\mathrm{B}$ is $4.73 \%$ and in panel $\mathrm{C}$ is $2.68 \%$. The apoptosis rate of GBC-SD-Bmil-si RNA is significantly higher than the other two groups.

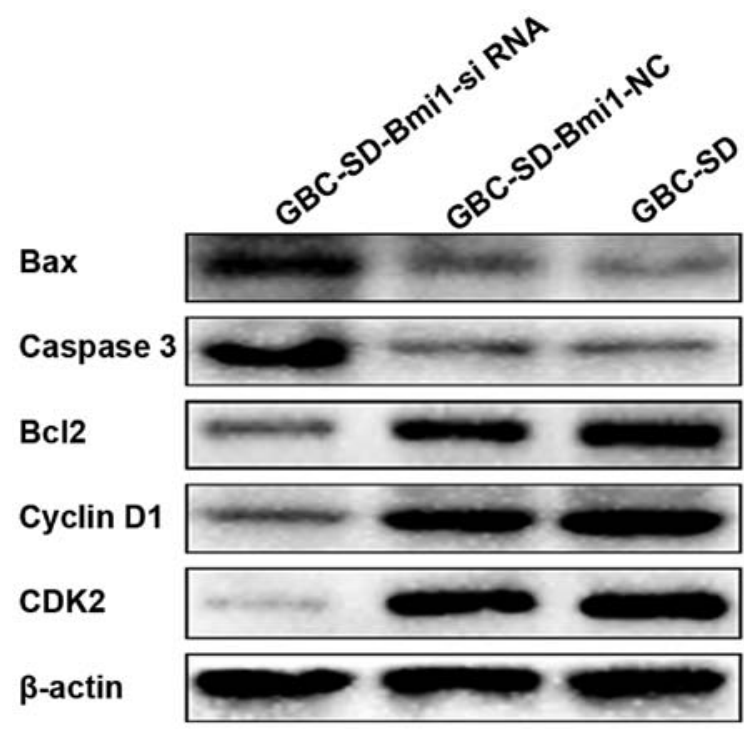

Figure 6. Expression of cyclin and apoptotic proteins in cells after Bim1-si RNA transfection.

carcinoma tissues was significantly higher than that in normal gallbladder tissues, and data analysis showed that the expression of Bmi-1 protein in gallbladder carcinoma tissues was associated with tumor differentiation degree and stage. There was no association with sex, age, presence of gallstones and other organ invasions. After transfecting Bmil-si RNA and Bmil-NC vector into gallbladder cancer cell line GBC-SD, RT-qPCR showed that Bmi-1 expression level in GBC-SD-Bmil-s RNA was significantly lower than that in GBC-SD-Bmil-NC and GBC-SD cells, which proved that Bmil-si RNA played an inhibitory role. Absorbance of GBC-SD-Bmi1-si RNA cells in CCK-8 assay was significantly lower than that in the two control groups. That is, after inhibiting the expression of Bmi-1, the growth cycle of gallbladder cancer cells is prolonged, thereby leading to decreased proliferation. Qin et al (15) and Becker et al (16) found that the cell cycle was arrested after downregulating Bmi-1 expression in a mouse lung cancer model, which was consistent with the results of this study. Flow cytometry showed that the apoptosis rate of GBC-SD-Bmil-si RNA cells was significantly higher than that of the two control groups. The results were consistent with the CCK-8 experiment, in which the apoptosis rate of the cells was higher than that of the control group. It was again demonstrated that inhibition of $\mathrm{Bmi}-1$ expression in gallbladder cancer cells can promote apoptosis of gallbladder cancer cell line GBC-SD. This was consistent with the results reported by Xiao and Deng (17) that after the expression of Bmi-l gene was downregulated by gene knockout technology, the proliferation and invasion ability of gastric cancer cells were weakened, which again proved that Bmi-1 can be a potential target for targeted treatment of gallbladder cancer. In addition, the cell cycle arrest of GBC-SD-Bmil-si RNA cells affects the proliferation of gallbladder cancer cells, suggesting that Bmi-1 may regulate cell cycle and affect cell proliferation by acting on cell cycle factors. It can also act on proapoptotic and anti-apoptotic proteins to affect the apoptosis process of gallbladder cancer cells. Therefore, we extracted the total protein of GBC-SD-Bmil-si RNA cells and detected the expression of a series of cell cycle factors, pro-apoptotic proteins and anti-apoptotic proteins. Results showed that compared with the two control groups, the expression level of anti-apoptotic protein Bcl-2 was decreased in GBC-SD-Bmi1-si RNA cells, and the expression level of proapoptotic protein Bax and caspase 3 was increased, and expression level of cyclin D1 and CDK2 was decreased. This result indicates that downregulation of Bmi-1 expression may affect the expression levels of cyclin D1 and CDK2 in gallbladder cancer cells, leading to a delay in cell proliferation cycle, and also a decrease in the expression of anti-apoptotic protein Bcl-2 in gallbladder cancer cells. Increased expression of the proapoptotic protein Bax and the apoptotic kinase caspase 3 led to an increase in apoptosis.

Studies have shown that imbalance between cell proliferation and apoptotic state plays an important role in the occurrence and development of most malignant tumors. Cell proliferation imbalance and cell cycle disorder may affect the occurrence and development of tumors. This study demonstrates that targeted inhibition of Bmi-1 expression can affect the proliferation and apoptosis of gallbladder cancer cells. The molecular mechanism is related to the decreased expression of cyclin D1 and CDK2, decreased expression of anti-apoptotic protein Bcl-2, and increased expression of proapoptotic protein Bax and caspase 3, which confirms that Bmi-1 is a potential target for clinical treatment of gallbladder cancer. However, more clinical studies on its mechanism are still needed. 


\section{Acknowledgements}

Not applicable.

\section{Funding}

The study was funded by the Qiqihar City Science and Technology Project.

\section{Availability of data and materials}

The datasets used and/or analyzed during the present study are available from the corresponding author on reasonable request.

\section{Authors' contributions}

$\mathrm{KJ}$ conceived the study, wrote the manuscript and was responsible for immunohistochemical staining for detection of Bmi-1 expression in gallbladder carcinoma. $\mathrm{HZ}$, WJ and $\mathrm{CZ}$ were responsible for western blot analysis and PCR. HZ and DS helped with flow cytometry and CCK- 8 assay. All authors read and approved the final manuscript.

\section{Ethics approval and consent to participate}

The study was approved by the Ethics Committee of The Second Affiliated Hospital of Qiqihar Medical University (Qiqihar, China). Patients who participated in this research had complete clinical data. Signed informed consents were obtained from the patients or the guardians.

\section{Patient consent for publication}

Not applicable.

\section{Competing interests}

The authors declare that they have no competing interests.

\section{References}

1. Kapoor VK: Gallbladder cancer: A global perspective. J Surg Oncol 93: 607-609, 2006

2. Wu XS, Shi LB, Li ML, Ding Q, Weng H, Wu WG, Cao Y, Bao RF, Shu YJ, Ding QC, et al: Evaluation of two inflammationbased prognostic scores in patients with resectable gallbladder carcinoma. Ann Surg Oncol 21: 449-457, 2014
3. Zhu AX, Hong TS, Hezel AF and Kooby DA: Current management of gallbladder carcinoma. Oncologist 15: 168-181, 2010.

4. Wakai T, Shirai Y, Yokoyama N, Nagakura S, Watanabe H and Hatakeyama K: Early gallbladder carcinoma does not warrant radical resection. Br J Surg 88: 675-678, 2001.

5. Yang GF, He WP, Cai MY, He LR, Luo JH, Deng HX, Guan XY, Zeng MS, Zeng YX and Xie D: Intensive expression of Bmi-1 is a new independent predictor of poor outcome in patients with ovarian carcinoma. BMC Cancer 10: 133, 2010.

6. He XT, Cao XF, Ji L, Zhu B, Lv J, Wang DD, Lu PH and Cui HG: Association between Bmil and clinicopathological status of esophageal squamous cell carcinoma. World J Gastroenterol 15: 2389-2394, 2009.

7. Luo M, Shen D-X, Guo X-T, Guan T and Chen X-D: Clinicopathological and prognostic significance of Bmi-1 expression in human cervical cancer. Acta Obstet Gynecol Scand 90: 737-745, 2011.

8. Livak KJ and Schmittgen TD: Analysis of relative gene expression data using real-time quantitative PCR and the 2(-Delta Delta C(T)) method. Methods 25: 402-408, 2001.

9. Lazcano-Ponce EC, Miquel JF, Muñoz N, Herrero R, Ferrecio C, Wistuba II, Alonso de Ruiz P, Aristi Urista G and Nervi F: Epidemiology and molecular pathology of gallbladder cancer. CA Cancer J Clin 51: 349-364, 2001.

10. Pandey M: Risk factors for gallbladder cancer: A reappraisal. Eur J Cancer Prev 12: 15-24, 2003.

11. Nandakumar A, Gupta PC, Gangadharan P, Visweswara RN and Parkin DM: Geographic pathology revisited: Development of an atlas of cancer in India. Int J Cancer 116: 740-754, 2005.

12. Misra S, Chaturvedi A, Misra NC and Sharma ID: Carcinoma of the gallbladder. Lancet Oncol 4: 167-176, 2003.

13. Hsing AW, Gao YT, Devesa SS, Jin F and Fraumeni JF Jr: Rising incidence of biliary tract cancers in Shanghai, China. Int J Cancer 75: 368-370, 1998

14. Ito H, Matros E, Brooks DC, Osteen RT, Zinner MJ, Swanson RS, Ashley SW and Whang EE: Treatment outcomes associated with surgery for gallbladder cancer: A 20 -year experience. J Gastrointest Surg 8: 183-190, 2004.

15. Qin L, Zhang X, Zhang L, Feng Y, Weng GX, Li MZ, Kong QL, Qian CN, Zeng YX, Zeng MS, et al: Downregulation of BMI-1 enhances 5-fluorouracil-induced apoptosis in nasopharyngeal carcinoma cells. Biochem Biophys Res Commun 371: 531-535, 2008.

16. Becker M, Korn C, Sienerth AR, Voswinckel R, Luetkenhaus K, Ceteci $\mathrm{F}$ and Rapp UR: Polycomb group protein Bmil is required for growth of RAF driven non-small-cell lung cancer. PLoS One 4: e4230, 2009.

17. Xiao J and Deng C: Knockdown of Bmi-1 impairs growth and invasiveness of human gastric carcinoma cells. Oncol Res 17: 613-620, 2009 